\title{
The future in the care of the cervical spine: interbody fusion and arthroplasty
}

\author{
Invited submission from the Joint Section Meeting on Disorders of the \\ Spine and Peripheral Nerves, March 2004
}

\author{
Praveen V. Mummaneni, M.D., and Regis W. Haid, M.D. \\ Department of Neurological Surgery, Emory University; and Atlanta Brain and Spine Care, \\ Atlanta, Georgia
}

\begin{abstract}
$\checkmark$ In the past 50 years tremendous advances have been made in the treatment of cervical disc disease with cervical fusion. Fusion rates have surpassed $95 \%$ after application of anterior cervical implants. Adjacent-segment degeneration, however, has plagued the long-term clinical success of cervical fusion.

Cervical arthroplasty has been introduced to maintain cervical motion and potentially avoid or minimize adjacentsegment degeneration. If cervical arthroplasty is successful, the long-term results of surgery for cervical disc disease may improve; however, there are associated drawbacks that must be overcome. Implant wear, fatigue, and failure have been reported in cases of large-joint arthroplasty, and research is underway to limit these problems in cervical arthroplasty.

In this article the authors trace the evolution of cervical fusion and the new technique of cervical arthroplasty. The nomenclature of cervical arthroplasty will also be introduced.
\end{abstract}

KEY WORDS • cervical disc • fusion • bone morphogenetic protein • arthroplasty

$\mathrm{T}$ HE human disc serves two biomechanical roles: transmitting loads and allowing a controlled range of motion for the neck. During the past 50 years, $\mathrm{ACDF}$ has been performed to treat cervical disc herniation. Although ACDF transmits loads, it limits the normal controlled range of motion of the cervical spine.

\section{Evolution of ACDF}

Anterior cervical discectomy and fusion was first described by Smith and Robinson ${ }^{16}$ and also by Cloward ${ }^{4}$ in the 1950s. Initial attempts were performed without anterior plate fixation. Initially, iliac crest autograft was placed as the interbody spacer. Although an excellent material to promote interbody fusion, it is associated with harvest site-related morbidity in up to $25 \%$ of patients. The potential for donor site infection and pain are limitations of its use. ${ }^{2,14}$ Consequently, allograft eventually replaced iliac crest autograft as the most typical choice for an interbody spacer.

When allograft is used for ACDF without anterior plate fixation, successful fusion has been reported in $90 \%$ of

Abbreviations used in this paper: $\mathrm{ACDF}=$ anterior cervical discectomy and fusion; PEEK = poly-ether-ether-ketone; rhBMP-2 = recombinant human bone morphogenetic protein-2. single-level surgeries; however, in cases requiring twolevel surgeries, the fusion rate decreases to $72 \%$ when allograft is used without supplemental plate fixation. ${ }^{12}$

Anterior cervical plate fixation significantly improves the successful arthrodesis after single-level ACDF. A 96\% fusion rate has been reported when allograft is combined with anterior cervical plate fixation. In cases requiring two-level surgery, a $91 \%$ fusion rate has been reported when allograft is used in conjunction with anterior plate fixation. ${ }^{12}$

Drawbacks of allograft interbody spacers include their limited supply, irregular dimensions, and risk of transmitting infection (viral or bacterial). Recently, synthetic materials have been developed in an effort to overcome these limitations.

New synthetic spacers, such as PEEK, are unlimited in supply, have regular dimensions, are nonabsorbable and radiolucent, and do not risk the transmission of infection from the donor. When PEEK interbody spacers are combined with rhBMP-2 and anterior cervical plate fixation, we have found a $100 \%$ successful fusion rate (Fig. 1). ${ }^{3}$

\section{Evolution of Cervical Arthroplasty}

Anterior cervical discectomy and fusion is currently the gold-standard treatment for herniated cervical discs. 
Arthrodesis, which was previously associated with fusion rates greater than $90 \%$ when allograft was combined with anterior cervical plate fixation, now approaches rates of $100 \%$ when the new synthetic materials such as PEEK and rhBMP-2 are used. The question arises: is cervical arthroplasty better than ACDF?

During the past decade, ACDF has been found to be associated with symptomatic adjacent-segment disease. Hilibrand, et al., ${ }^{10,11}$ reported that surgical intervention was necessary for $2.9 \%$ of patients annually because of symptomatic adjacent-segment disease following ACDF. Furthermore, they found that 10 years after ACDF, 25\% of patients reported symptoms due to adjacent-segment disease. In addition, Goffin, et al., ${ }^{9}$ reported that in $92 \%$ of fusion-treated patients radiographic evidence of adjacentsegment degenerative disc disease was demonstrated 5 years postoperatively. The cause of this adjacent-segment disease appears to be the abnormal kinematics (higher shear strains) that occur at levels adjacent to anterior cervical fusions. ${ }^{13}$ Cervical disc arthroplasty, therefore, could be beneficial because adjacent-segment disease might be avoided by maintaining normal neck mobility.

Attempts at replacing a disc with an artificial cervical disc were made more than 10 years ago. ${ }^{5}$ Early designs of these implants were modeled on artificial joints (arthroplasties) implanted by orthopedists in the knees, hips, and shoulders.

In large-joint replacement procedures involving knees and hips, the implants are subject to repetitive stresses and generate wear-related debris. Tribology (the study of friction, lubrication, and wear of interacting surfaces in relative motion) has been a primary focus for the developers of large-joint prostheses in recent years. Like other total joints, artificial disc prostheses have articulating surfaces that will wear down during the life of the implant. With the potential increase in use of articulating devices in the cervical spine in coming years, it is necessary to evaluate the amount of wear debris generated in in vivo loading conditions. Tribology is central to the success of cervical arthroplasty because artificial disc designs that are prone to excessive wear debris may contribute to metal toxicity and foreign-body reactions, which would make them suboptimal for application in humans. In general, artificial joints that induce excessive wear debris may stimulate a host response to generate macrophages and multinucleated giant cells (inflammatory reaction) to surround the wear debris. These cells can release cytokines that initiate a cascade that ultimately could result in osteolysis and loosening of the implant. In addition to wear debris, several other potential drawbacks may limit the widespread use of cervical arthroplasty. These drawbacks include material fatigue and catastrophic failure of the artificial joint in traumatic situations.

To quantify the amount of wear debris generated by these devices, wear testing has been recently performed on two different cervical prostheses, a metal-on-metal disc (PRESTIGE Artificial Disc; Medtronic Sofamor Danek, Memphis, TN) and a polyurethane-on-metal disc (BRYAN Artificial Disc; Medtronic Sofamor Danek) under normal physiological loads and motions. Testing was conducted to a total of 20 million cycles in a cervical spine simulator that applied the loads and motions associated with activities of daily living. It was found that the mean

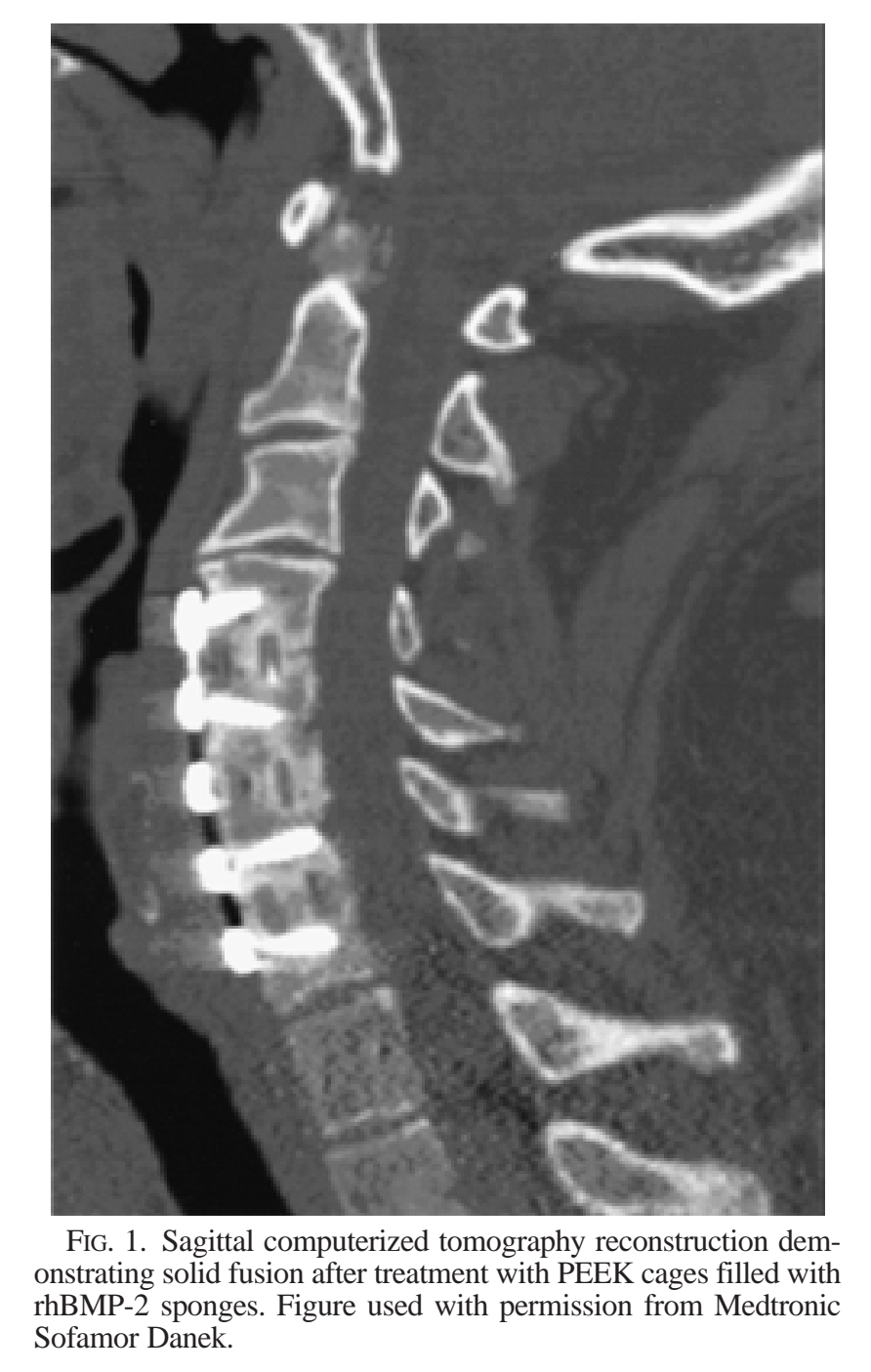

wear rate for the metal-on-metal device was $0.46 \pm 0.29$ $\mathrm{mm}^{3} /$ million cycles, whereas that for the polyurethane-onmetal device was $0.97 \pm 0.87 \mathrm{~mm}^{3} /$ million cycles. These rates are orders of magnitude less than rates of currently available large-joint prostheses. Furthermore, evaluation of a cervical arthroplasty device explanted after 3.25 years has shown the wear equivalent to be approximately 311,000 cycles of in vitro wear testing. .,6,17 $^{-17}$

\section{Nomenclature of Cervical Arthroplasty}

During the 1990s, numerous new-generation artificial discs were created. To track the evolving generations of artificial cervical discs, the Cervical Spine Study Group developed a new nomenclature system for cervical arthroplasty. Currently, artificial discs are classified into three types: non-, uni-, and biarticulating. The implant may consist of a metal-on-metal design (Fig. 2), a metal-on-polymer (that is, ultra-high molecular-weight polyethylene) (Fig. 3), a ceramic-on-polymer, or a ceramic-on-ceramic design. The disc is either modular (having replaceable components) or nonmodular (lacking replaceable compo- 


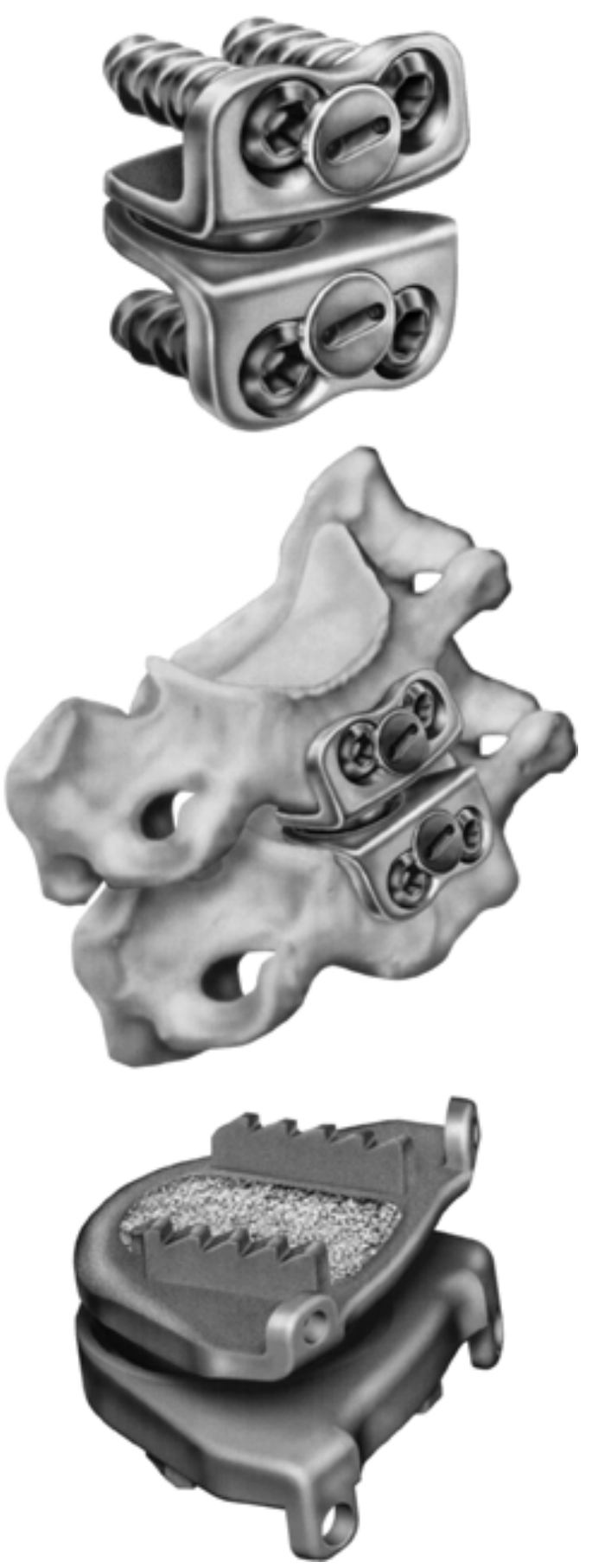

FIG. 2. Illustrations of cervical discs. Upper: The Prestige ST cervical disc. Note the metal-on-metal design. Center: The Prestige ST disc implanted in the cervical spine. Lower: The Prestige LP disc, the next-generation metal-on-metal design with a lower profile. Illustrations used with permission from Medtronic Sofamor Danek.

nents), and some are used in conjunction with supplemental vertebral body screw fixation, whereas others are not. Certain artificial disc designs promote biological bone ingrowth at the disc-endplate interface. Artificial discs may be constrained in terms of motion, or they may be

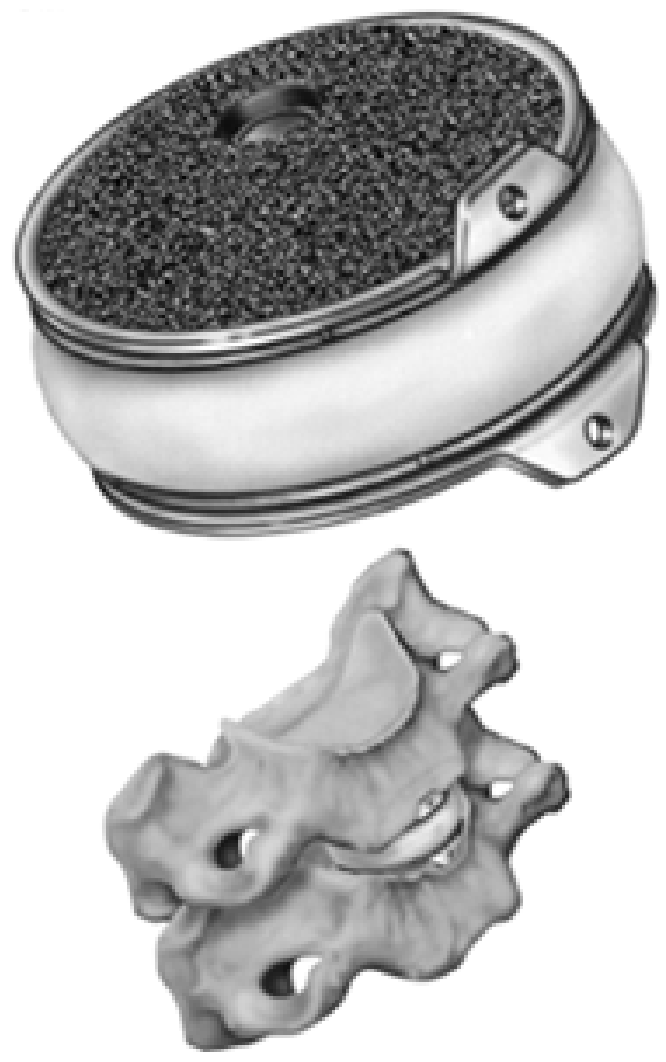

FIG. 3. Illustrations of the metal-on-polymer Bryan cervical disc alone (upper) and implanted in the cervical spine (lower). Illustrations used with permission from Medtronic Sofamor Danek.

semi- or unconstrained. Consequently, they may be categorized based on the following criteria: articulation, material, design, fixation, and kinematics (Fig. 4).

\section{Clinical Trials}

Investigators in European and Australian clinical trials have demonstrated superior results when using the metalon-metal and metal-on-polymer discs compared with ACDF; these results were based on neck disability index and arm pain intensity visual analog scale scores as well as neurological status. ${ }^{5,7,8,15,18,19}$ Excessive metal debris, material fatigue with fracture, and catastrophic failure have not been shown to be problematic in the European trials, the results of which indicate that the advantages (motion maintenance and potential improved clinical outcome) of arthroplasty outweigh its disadvantages (wear debris, material fatigue, and joint failure).

In the US, three artificial discs are undergoing prospective, randomized clinical trials in which outcomes are being compared with those demonstrated after cervical fusion. They include the Prestige Artificial Disc (Fig. 2), Bryan Artificial Disc (Fig. 3), and the ProDisc-C (Synthes, Paoli, PA) (Fig. 5). Based on the accrual of these Class I data derived from comparing cervical arthroplasty with cervical interbody fusion, clinicians will be able to determine whether arthroplasty is equivalent or superior 


\section{Artificial Disc Nomenclature}

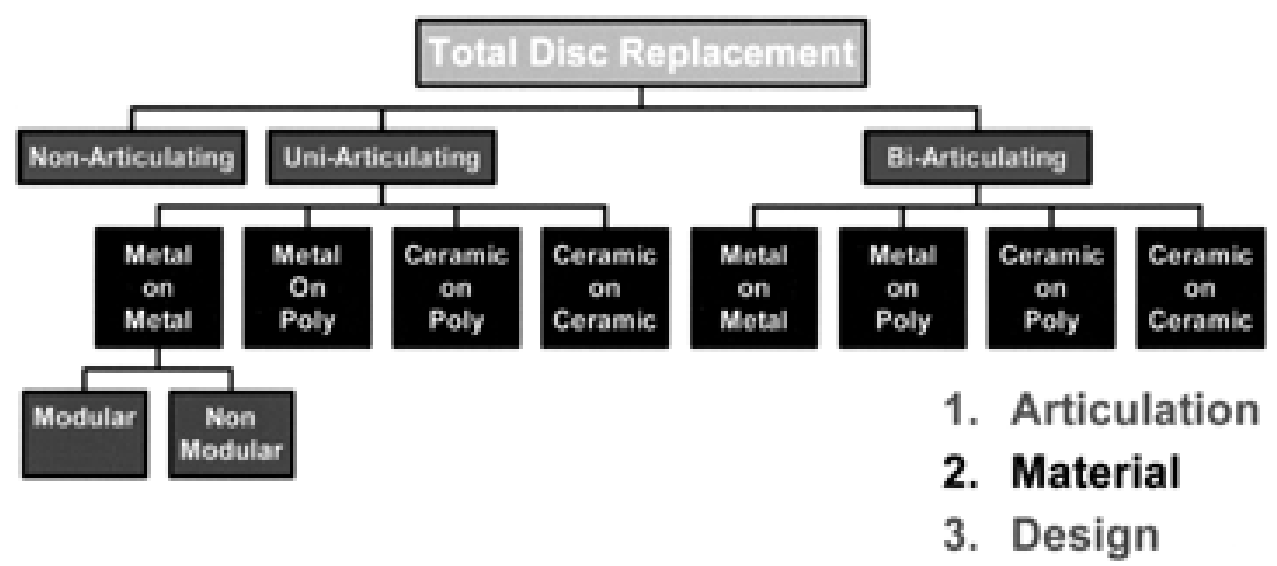

FIG. 4. The Cervical Spine Study Group's artificial cervical disc nomenclature allows for classification of the different designs for cervical implants.

to arthrodesis.

\section{Conclusions}

In the last half century, the philosophy of spine surgeons was to undertake cervical fusion to manage symptomatic cervical disc herniations. The focus of research was to improve fusion rates to $100 \%$. Spinal implants improved the fusion rates significantly while minimizing morbidity (for example, iliac crest donor site pain).

In the next 50 years spine surgeons will likely witness the emergence of a new philosophy, centered around the maintenance of motion when treating spinal segmental disease, which will revolutionize the treatment paradigms in clinical use. Certain obstacles, however, must be over-

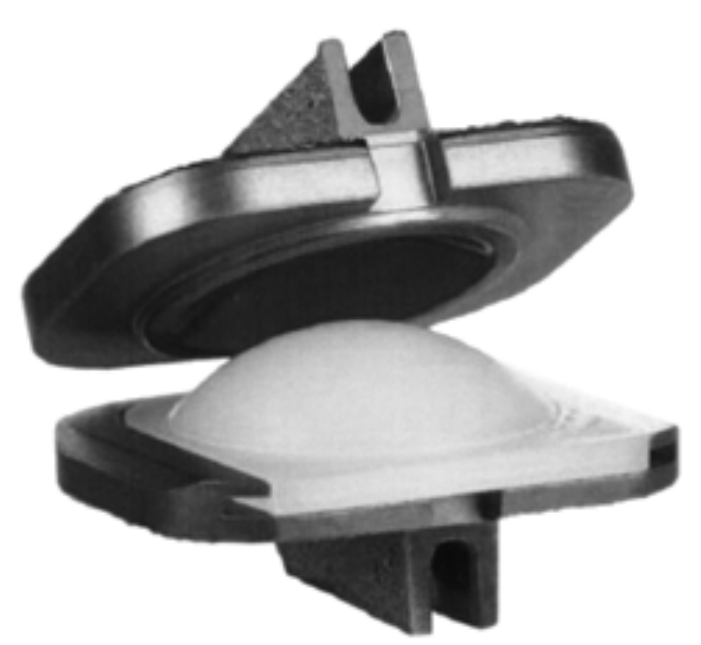

FIG. 5. Illustration of the metal-on-polymer ProDisc-C. This image is a trademark of Synthes Spine, Ltd. Permission to reproduce it must be obtained from Synthes (Paoli, PA). come to realize the goals of arthroplasty. Material wear, fatigue, and failure must be minimized. Current research is focused on the tribology of cervical arthroplasty, and strides are being made to overcome the obstacles to maintaining cervical motion.

\section{Acknowledgments}

We are grateful to Regina Carder, Sherry Ballenger, and Drew Imhulse for assistance with the manuscript and figures.

\section{References}

1. Anderson PA, Rouleau JP, Bryan VE, et al: Wear analysis of the Bryan Cervical Disc prosthesis. Spine 28:S186-S194, 2003

2. Banwart JC, Asher MA, Hassanein RS: Iliac crest bone graft harvest donor site morbidity. A statistical evaluation. Spine 20: 1055-1060, 1995

3. Boakye M, Mummaneni PV, Rodts GE, et al: Anterior cervical discectomy and fusion using PEEK and BMP. Platform Presentation. Joint Section on Disorders of the Spine and Peripheral Nerves. San Diego, CA. 2004 Mar

4. Cloward RB: The anterior approach for removal of ruptured cervical disks. J Neurosurg 10:602-617, 1958

5. Cummins BH, Robertson JT, Gill SS: Surgical experience with an implanted artificial cervical joint. J Neurosurg 88:943-948, 1998

6. DiAngelo DJ, Robertson JT, Metcalf NH, et al: Biomechanical testing of an artificial cervical joint and an anterior cervical plate. J Spinal Disord Tech 16:314-323, 2003

7. Goffin J, Casey A, Kehr P, et al: Preliminary clinical experience with the Bryan Cervical Disc Prosthesis. Neurosurgery 51: 840-847, 2002

8. Goffin J, Van Calenbergh F, van Loon J, et al: Intermediate follow-up after treatment of degenerative disc disease by the Bryan Cervical Disc Prosthesis: single-level and bi-level. Spine 28:2673-2678, 2003

9. Goffin J, van Loon J, Van Calenbergh F, et al: Long-term results after anterior cervical fusion and osteosynthetic stabilization for fractures and/or dislocations of the cervical spine. $\mathbf{J}$ Spinal Disord 8:499-508, 1995

10. Hilibrand AS, Carlson GD, Palumbo M, et al: Radiculopathy and myelopathy at segments adjacent to the site of a previous 


\section{Cervical interbody fusion and arthroplasty}

anterior cervical arthrodesis. J Bone Joint Surg Am 81: 519-528, 1999

11. Hilibrand AS, Yoo JU, Carlson GD, et al: The success of anterior cervical arthrodesis adjacent to a previous fusion. Spine 22:1574-1579, 1997

12. Kaiser MG, Haid RW Jr, Subach BR, et al: Anterior cervical plating enhances arthrodesis after discectomy and fusion with cortical allograft. Neurosurgery 50:229-238, 2002

13. Matsunaga S, Kabayama S, Yamamoto T, et al: Strain on intervertebral discs after anterior cervical decompression and fusion. Spine 24:670-675, 1999

14. Sawin PD, Traynelis VC, Menezes AH: A comparative analysis of fusion rates and donor-site morbidity for autogeneic rib and iliac crest bone grafts in posterior cervical fusions. J Neurosurg 88:255-265, 1998

15. Sekhon L: Cervical arthroplasty in the management of spondylotic myelopathy. J Spinal Disord Tech 16:307-313, 2003

16. Smith G, Robinson R: The treatment of certain cervical-spine disorders by anterior removal of the intervertebral disc and interbody fusion. J Bone Joint Surg Am 49:607-622, 1958
17. Traynelis V, et al: Wear characteristics of the Prestige Cervical Disc: Laboratory testing and clinical analysis. Presented at Twentieth Annual Joint Section on Disorders of the Spine and Peripheral Nerves. San Diego, CA. 2004 Mar

18. Wigfield C, Gill S, Nelson R, et al: Influence of an artificial cervical joint compared with fusion on adjacent-level motion in the treatment of degenerative cervical disc disease. J Neurosurg (Spine 1) 96:17-21, 2002

19. Wigfield CC, Gill SS, Nelson RJ, et al: The new Frenchay Artificial Cervical Joint: results from a two-year pilot study. Spine 27:2446-2452, 2002

Address reprint requests to: Regis Haid, M.D., Atlanta Brain and Spine Care, Atlanta, Georgia 30308. 